\title{
Peroxisome proliferator activator receptor gamma coactivator-1alpha (PGC-1 $\alpha$ ) improves motor performance and survival in a mouse model of amyotrophic lateral sclerosis
}

Wei Zhao ${ }^{1,2}$, Merina Varghese ${ }^{1,2}$, Shrishailam Yemul ${ }^{1,2}$, Yong Pan $^{1,2}$, Alice Cheng ${ }^{1,2}$, Paul Marano ${ }^{1}$, Sadiq Hassan ${ }^{1}$, Prashant Vempati ${ }^{1,2}$, Fei Chen ${ }^{1,2}$, Xianjuan Qian ${ }^{1,2}$ and Giulio M Pasinetti ${ }^{1,2^{*}}$

\begin{abstract}
Background: Amyotrophic lateral sclerosis (ALS) is a devastating neurodegenerative disease that affects spinal cord and cortical motor neurons. An increasing amount of evidence suggests that mitochondrial dysfunction contributes to motor neuron death in ALS. Peroxisome proliferator-activated receptor gamma co-activator-1 $\alpha$ (PGC$1 \alpha)$ is a principal regulator of mitochondrial biogenesis and oxidative metabolism.

Results: In this study, we examined whether PGC-1 $\alpha$ plays a protective role in ALS by using a double transgenic mouse model where PGC-1 $\alpha$ is over-expressed in an SOD1 transgenic mouse (TgSOD1-G93A/PGC-1 $\alpha$ ). Our results indicate that PGC-1 $\alpha$ significantly improves motor function and survival of SOD1-G93A mice. The behavioral improvements were accompanied by reduced blood glucose level and by protection of motor neuron loss, restoration of mitochondrial electron transport chain activities and inhibition of stress signaling in the spinal cord.

Conclusion: Our results demonstrate that PGC-1 $\alpha$ plays a beneficial role in a mouse model of ALS, suggesting that PGC-1 $\alpha$ may be a potential therapeutic target for ALS therapy.
\end{abstract}

\section{Background}

Amyotrophic lateral sclerosis (ALS), or Lou Gehrig's disease, is one of the most common adult-onset neurodegenerative diseases. ALS results in the progressive loss of upper and lower motor neurons and gradual muscle weakening, which ultimately will lead to paralysis and death. No apparent genetic links have been found in the majority of the ALS patients, but the disease was inherited in the remaining cases (about 10\%) [1]. The first ALS gene identified was the copper-zinc superoxide dismutase (SOD1), and it is the most extensively studied gene. SOD1 accounts for about $20 \%$ of familial ALS cases [2]. Mutations cause SOD1 to undergo toxic misfolding and aggregation, possibly causing a heightened presence of reactive oxygen species. Among more than 90 mutations on the SOD1 gene that have been

\footnotetext{
* Correspondence: giulio.pasinetti@mssm.edu

1 Department of Neurology, Mount Sinai School of Medicine, New York, NY 10029, USA

Full list of author information is available at the end of the article
}

associated with ALS through various studies, the mutation of glycine 93 to alanine (G93A) has been particularly well-studied $[3,4]$. It has been used to create the popular SOD1-G93A transgenic mouse model of ALS [5].

Many mechanisms are involved in the pathology of ALS, including glutamate toxicity, oxidative stress, defective axonal transport, glia cell pathology and mitochondrial dysfunction. The mitochondrion is a vital organelle that performs multiple functions in aerobic cells. It is the major site of ATP production, maintaining calcium homeostasis, participating in calcium signaling, and regulating intrinsic apoptosis. Therefore, mitochondrial malfunction presents multiple effects on the cell, especially neurons with an elevated susceptibility to aging and stress. Mitochondrial pathology is a key player among working hypotheses in the study of ALS [6-8]. Altered mitochondrial electron transport chain (ETC) enzyme activities have been observed in ALS patients and ALS mouse models [4,9-12]. Treatment with

\section{C) Biomed Central}


creatine, which could enhance mitochondrial activity, was found to improve motor performance and survival time in SOD1-G93A mice [13].

The transcriptional coactivator peroxisome proliferator-activated receptor gamma co-activator- $1 \alpha$ (PPARGC1A or PGC-1 $\alpha$ ) is a master regulator of mitochondrial biogenesis and oxidative metabolism [14]. In PGC-1 $\alpha$ knockout mice, expression of genes that are responsible for mitochondrial respiration is markedly dulled and mitochondrial enzymatic activities are also decreased [15].

In this study, we crossed PGC-1 $\alpha$ transgenic animal with SOD1-G93A transgenic animal to test the potential effect of PGC-1 $\alpha$ in this mouse model of ALS.

\section{Results}

Characterization of PGC- $1 \alpha$ transgenic animal

Since the PGC-1 $\alpha$ gene inserted is on a rat neuron-specific enolase (NSE) promoter, we first examined the expression of inserted human PGC-1 $\alpha$ in the mouse spinal cord. As expected, we only found human PGC-1 $\alpha$ expression in the spinal cord of PGC-1 $\alpha$ single transgenic and SOD1-G93A/PGC-1 $\alpha$ double transgenic animals (Figure 1A). Then we looked at the expression level of PGC-1 $\alpha$ in the brain. A significant overexpression of PGC-1 $\alpha$ was observed in the hippocampus and cortex of PGC-1 $\alpha$ transgenic mice (Figure 1B). We also examined SOD activity in these animals. A higher SOD enzymatic activity was observed in SOD1-G93A transgenic animals as previously described [16], but not in other experimental groups (data not shown).

PGC-1 $\alpha$ Reduced Blood Glucose Level in SOD1-G93A Mice Impaired glucose tolerance has been reported in ALS patients [17]. To see whether presence of PGC-1 $\alpha$ could have any beneficial effect in the glucose level, we performed a glucose tolerance test in the WT, PGC-1 $\alpha$, SOD1-G93A and SOD1-G93A/PGC-1 $\alpha$ transgenic animals. We first compared the fasting blood glucose levels between the four groups (Figure 1C) and found that SOD1-G93A/PGC-1 $\alpha$ double transgenic animals had a significantly lower baseline glucose reading than the SOD1-G93A animals $(100.8 \pm 6.111$ vs. $69.00 \pm 7.382$ $\mathrm{mg} / \mathrm{dL}, \mathrm{N}=5, \mathrm{p}=0.0106)$. We also recorded their
A
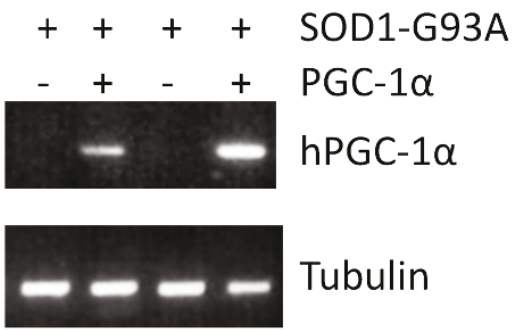

Tubulin
B

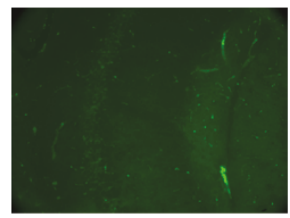

$\operatorname{TgPGC}-1 \alpha$
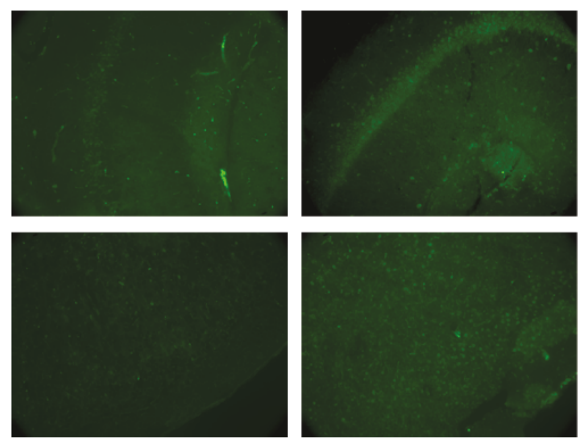

Hippocampus

Cortex
C

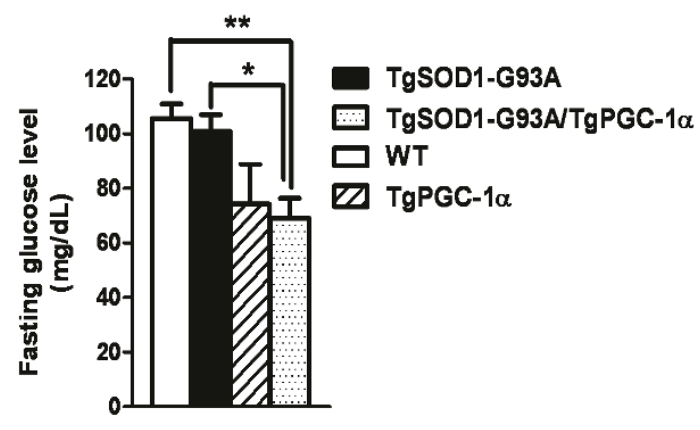

D

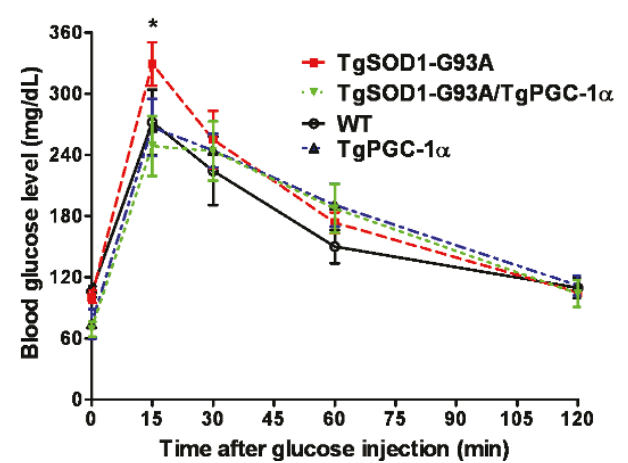

Figure 1 PGC- $1 \alpha$ expression and blood glucose level in transgenic animals. (A) Expression of human PGC- $1 \alpha$ transcript in the spinal cord; (B) Overexpression of PGC-1 $\alpha$ in the brain of PGC-1 $\alpha$ transgenic animal; (C) Base line blood glucose level in WT, PGC-1 $\alpha$, SOD1-G93A and SOD1G93A/PGC-1 $\alpha$ animals ( $* p<0.05$ ); (D) Glucose tolerance test of WT, PGC-1 $\alpha$, SOD1-G93A and SOD1-G93A/PGC-1 $\alpha$ animals. 
glucose levels at $15,30,60$, and 120 minutes after glucose injection (2 $\mathrm{mg}$ glucose per g body weight). Although two way ANOVA analysis did not reveal a major difference between the SOD1-G93A single transgenic animals and the SOD1-G93A/PGC-1 $\alpha$ double transgenic animals, (Figure 1D), a significantly lower peak glucose level (at $15 \mathrm{~min}$ ) was observed in the SOD1-G93A/PGC-1 $\alpha$ double transgenic animals (Bonferroni post-test, $\mathrm{p}<0.05$ ).

\section{PGC-1 $\alpha$ Improved Motor Performance and Survival in SOD1-G93A Mice}

Important behavioral and physiological characteristics of SOD1-G93A transgenic mice include impaired motor performance, weight loss and reduced survival as compared to the wild-type. We assessed motor performance of the single and double transgenic animals using an accelerating rotarod apparatus for mice. At pre-symptomatic/midsymptomatic stages, there was no apparent difference in the motor function between SOD1-G93A and SOD1G93A/PGC- $1 \alpha$ double transgenic animals. Remarkable improvement in the motor function was observed in the double transgenic as compared to the ALS mice at postsymptomatic stage (week 17) (latency of $104.3 \pm 14.42$ vs. $37.13 \pm 15.80 \mathrm{~s}, \mathrm{~N}=8, \mathrm{p}=0.0078$ ) (Figure $2 \mathrm{~A}$ ).

We also assessed the survival of the experimental animals. SOD1-G93A/PGC-1 $\alpha$ double transgenic animals have a median survival of 139 days, which is significantly longer than SOD1-G93A animals with a median survival of 129 days (Figure 2B) as determined by the Mantel-Cox test $(\mathrm{p}=0.0064)$.

The body weight of each mouse was monitored weekly during the study period (Figure 2C). We compared the peak weight at pre-symptomatic stage (day 87 ) with the weight at their post-symptomatic stage (day 127), and found that SOD1-G93A/PGC-1 $\alpha$ double transgenic animals had a significantly less weight loss (percentage of peak weight) than their SOD1-G93A littermates (twoway t-test, $\mathrm{p}=0.0214$ ) (Figure $2 \mathrm{D}$ ).

\section{PGC-1 $\alpha$ Protected Against Motor Neuron Death in SOD1- G93A Mice}

To determine whether PGC- $1 \alpha$ can protect against the motor neuron loss that accompanies the clinical symptoms of ALS, we counted the number of motor neurons in the lumbar spinal cord in age and gender matched WT, SOD1-G93A, PGC- $1 \alpha$ and SOD1-G93A/PGC- $1 \alpha$ mice at post-symptomatic stage (day 110) (Figure 3A). Wild type animals had a mean of $20.40 \pm 0.5099$ ( $\mathrm{N}=$ 5) motor neurons per spinal cord section. As expected, motor neuron counts in SOD1-G93A mice were significantly lower compared to WT $(\mathrm{p}<0.01)$. In SOD1G93A/PGC- $1 \alpha$ double transgenic mice, there were significantly more motor neurons in the ventral horn compared to those in the SOD1-G93A mice (22.25 \pm 1.548 vs. $13.00 \pm 1.414, \mathrm{p}=0.003$ ) (Figure $3 \mathrm{~B}$ ).

\section{PGC-1 $\alpha$ Restored Mitochondrial Electron Transport Chain Activities in the Spinal Cord}

To evaluate the effect of PGC- $1 \alpha$ in mitochondrial ETC activities, we isolated the spinal cords of age, gendermatched WT, SOD1-G93A, PGC-1 $\alpha$ and SOD1-G93A/ PGC-1 $\alpha$ animals. In situ histochemical assays were performed in the lumbar spinal cord sections as previously described $[13,18]$. We detected a decrease of complex activities in the ventral horn of lumbar spinal cord in mutant SOD1-G93A animals as compared to their wildtype littermates. Notably, SOD1-G93A/PGC-1 $\alpha$ double transgenic animals showed a similar level of complex I (Figure 4A, B) and complex IV activities (Figure 4C, D) as wild-type animals, suggesting that the presence of PGC- $1 \alpha$ attenuated the mitochondrial ETC transport defect in mutant ALS animals. No significant improvement of complex II activity was observed in SOD1G93A/PGC-1 $\alpha$ double transgenic animals when compared to SOD1-G93A animals (data not shown).

\section{PGC-1 $\alpha$ Decreased Phosphorylation of JNK and p38 MAPK in SOD1-G93A Mice}

Since hyper-phosphorylation of stress-activated kinases JNK (c-jun N-terminal kinase) and p38 MAPK has been demonstrated in SOD1-G93A mice [13,19,20], we used a bead-based multiplex luminex assay to examine the phosphorylation of JNK (Thr183/Tyr 185) and p38 (Thr180/Tyr182). In spinal cord lysates of SOD1-G93A/ PGC- $1 \alpha$ double transgenic animals, significantly less amount of phospho-JNK (Figure 5A, p $=0.0025$ ) or phospho-p38 (Figure 5B, p $=0.0064$ ) was detected as compared to the single transgenic mice.

\section{Discussion}

Our study demonstrated that SOD1-G93A/PGC-1 $\alpha$ double transgenic animals showed significant improvements in the clinical signs of ALS. The improvement of motor performance in SOD1-G93A/PGC-1 $\alpha$ double transgenic animals was accompanied by a significant preservation of motor neurons and mitochondrial electron transport chain activities in the ventral horn of the lumbar spinal cord. Additionally, SOD1-G93A/PGC-1 $\alpha$ double transgenic animals showed remarkably less weight loss at their end stages and had a notably longer life span as compared to their SOD1-G93A littermates.

Transport of materials (protein and organelles) between the cell body and neuron processes is essential to signal transduction and neuronal survival. Disruption of slow axonal transport of the cytoskeleton is one of the earliest pathological events in mutant SOD1 mice [21]. Fast axonal transport is responsible for transporting membrane-bound 


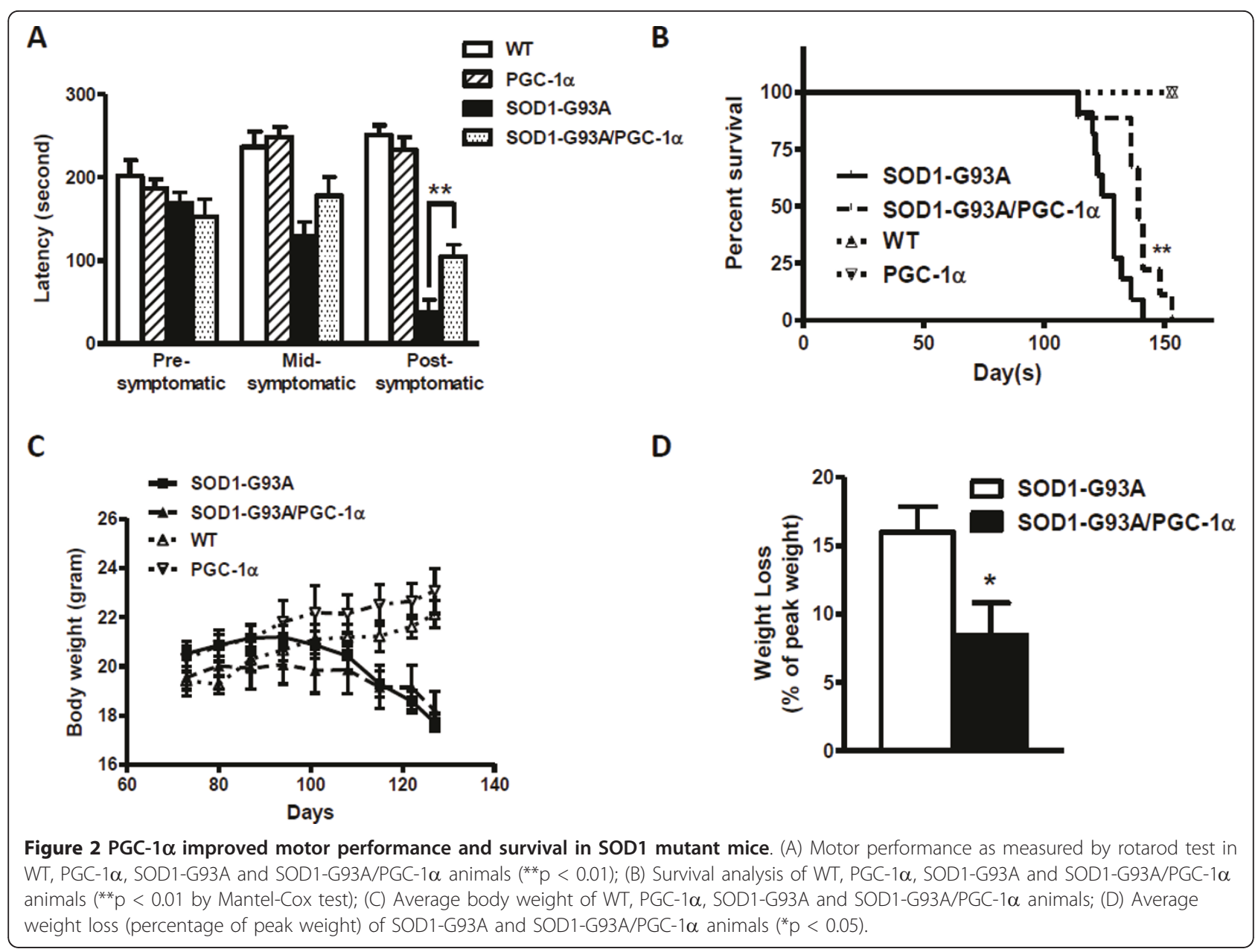

organelles, such as mitochondria, to maintain axonal and synaptic function. While it remains unclear how impairment of axonal transport causes motor neuron dysfunction and degeneration, some transport cargos such as neurotrophic factors, signaling molecules and mitochondria are obvious targets. Increased stress signaling (p-JNK, caspase- 8 and p75NTR) was recently found in SOD1G93A mice [19]. The p38 stress-activated kinase is activated and phosphorylates neurofilaments in SOD1-G93A mice [20,22]. p38 is also involved in regulating fast axonal transport including transport of mitochondria [23,24]. Our data showed a significant decrease of phosphorylation of JNK at Thr183/Tyr185 and p38 MAPK at Thr180/Tyr182, suggesting that the neuroprotective effect of PGC-1 $\alpha$ in SOD1-G93A mice might partially work through inhibiting the stress-activated signaling pathway and/or regulating mitochondria transport.

A growing amount of evidence identifies PGC- $1 \alpha$ as a potential therapeutic target in neurodegenerative diseases, including Alzheimer's disease (AD), Parkinson's disease (PD), and Huntington's disease (HD). Genome-wide expression studies revealed that PGC-1 $\alpha$ might be a therapeutic target for early intervention in PD [25]. Previous studies from our lab showed that PGC- $1 \alpha$ expression decreased in AD patient brain as a function of dementia [26]. PGC-1 $\alpha$ is implicated to play a key role in controlling energy metabolism in the early stages of HD pathogenesis $[27,28]$. To date there is no direct evidence that PGC- $1 \alpha$ plays a role in ALS pathogenesis. However some circumstantial evidence suggests that this represents a line of investigation worth pursuing. For instance, thiazolidinediones (TZDs) such as rosiglitazone and pioglitazone, which induce PGC- $1 \alpha$ expression and activate the PPAR $\gamma$ pathway have been shown to be beneficial in the SOD1 transgenic mouse model of ALS by two independent research groups [29,30]. Our in vivo evidence, for the first time demonstrates the neuro-protective role of PGC- $1 \alpha$ in an ALS mouse model, suggesting that PGC-1 $\alpha$ might be a potential therapeutic target for early intervention in ALS.

\section{Methods}

Experimental animals

Rat neuron-specific enolase (NSE) promoter plasmid containing hPGC-1 $\alpha$ was constructed by inserting 3.1 

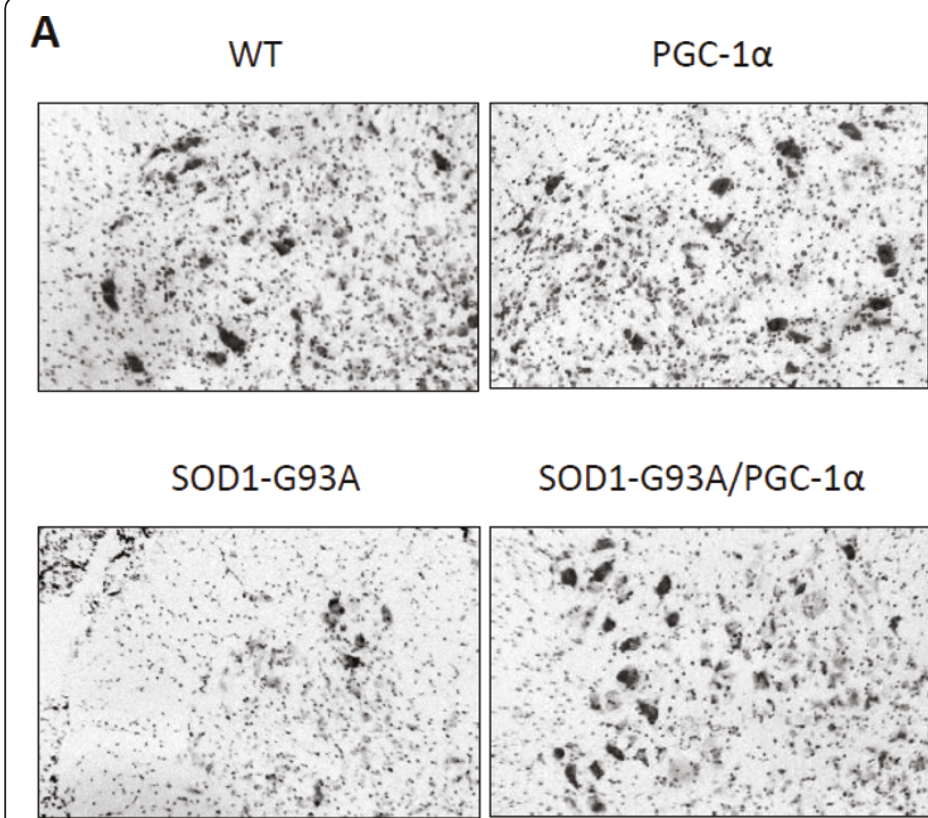

SOD1-G93A/PGC-1 $\alpha$

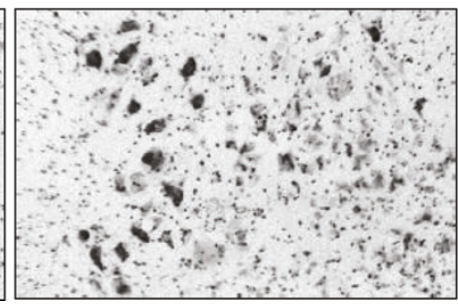

Figure 3 Nissl-stained motor neuron count in the lumbar spinal cord. The effect of the PGC-1 $\alpha$ on neuron numbers in SOD1-G93A transgenic mice at post-symptomatic stage (day 110) was examined following Nissl-staining. (A) Photomicrographs of representative Nissl-stained sections through the ventral horns of the lumbar spinal cord from wild-type (WT), SOD1-G93A, PGC-1 $\alpha$ and SOD1-G93A/PGC-1 $\alpha$ double transgenic mice. (B) Motor neuron counts in lumbar spinal cord (data $=$ Mean $\pm S E, n=5,{ }^{* *} p<0.05$ ).

kb cDNA fragment with entire coding region of hPGC$1 \alpha$ (NM_013261.2, OriGene Technologies, Inc. Rockville, MD) in Not I site of the plasmid vector. A cassette of $\sim 8 \mathrm{~kb}$ Sall fragment containing NSE promoter and hPGC- $1 \alpha$ was gel purified and microinjected into onecell mouse egg (C57BL6 $\times$ SJL)as described previously [31,32]. TgPGC-1 $\alpha$ founders were identified by PCRbased genotyping.

Male TgSOD1-G93A mutant transgenic mice (C57BL6 $\times$ SJL) were purchased from the Jackson Laboratory and bred with female PGC-1 $\alpha$ transgenic mice in our transgenic mouse facility to generate TgSOD1-G93A/TgPGC-1 $\alpha$ double transgenic mice and their TgSOD1-G93A, TgPGC-1 $\alpha$ or wild-type littermates. Mice were housed on a 12-hourlight, 12-hour-dark cycle and allowed ad libitum access to food. Mice were weighed weekly starting from 8 weeks of age. The survival study endpoint was defined as meeting any one of the following conditions: no spontaneous breathing or movement for 60 seconds with no response to pain; the animal is unable to roll over the normal position within 10 seconds following a push over; or complete hind limb paralysis. The Institutional Animal Care Committee of Mount Sinai School of Medicine reviewed and approved all experimental protocols used in this study.

\section{Immunostaining}

The brains of 5 months old Wild type and Tg2576 mice were dissected, cut into two hemispheres and fixed in
B

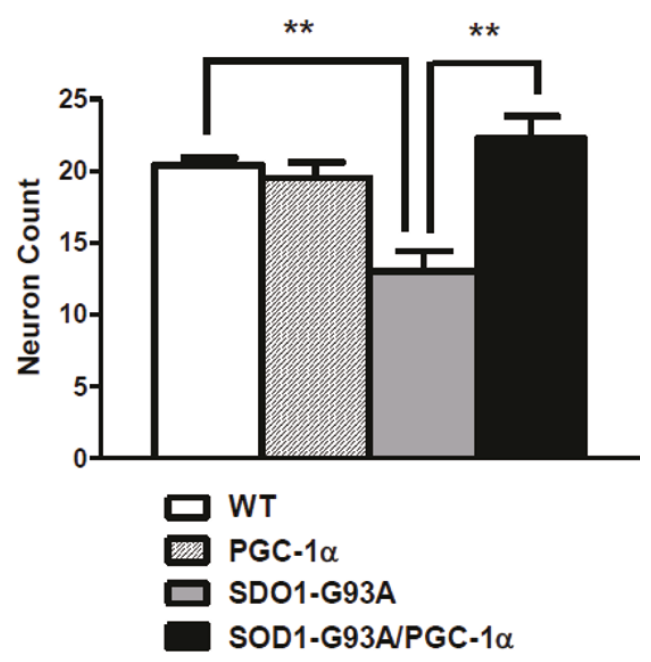

4\% Paraformadehyde. After extensive wash with PBS, equilibrated with $30 \%$ sucrose and embedded in Tissue Freezing Medium (Triangle Biomedical Sciences). The frozen brains were transversely sectioned $(14 \mathrm{uM})$. The tissue sections were incubated with PGC- $1 \alpha$ antibody (Santa Cruz Technology, H-300, 1:500 dilution) overnight at $4^{\circ} \mathrm{C}$. The sections were then washed and incubated with FITC-conjugated secondary antibody (1:250 dilution) for 1 hour. Following several washes with PBS, images were acquired under fluorescence microscope.

\section{Motor Function Assessment}

TgSOD1-G93A/TgPGC-1 $\alpha$ mice and TgSOD1-G93A mice were tested on an accelerating rotarod (7650 Ugo Basile Biological Research Apparatus, Comerio, Italy) as previously described. In brief, mice are placed onto a grooved cylinder (facing away from the experimenter) rotating at a predetermined speed that incrementally increases to a maximal rotation at 300s; the time maintained on the rod by each mouse (latency) is then recorded (300 s max). A diminishing latency indicates declining performance and at values of $0 \mathrm{~s}$ is suggestive of severe muscular weakness and impaired coordination. Mice were tested beginning at 80 days of age weekly until they could no longer perform the test. Before testing, mice underwent a 1 week training period wherein they were introduced to the apparatus and handled by the experimenter daily. Testing was conducted during 


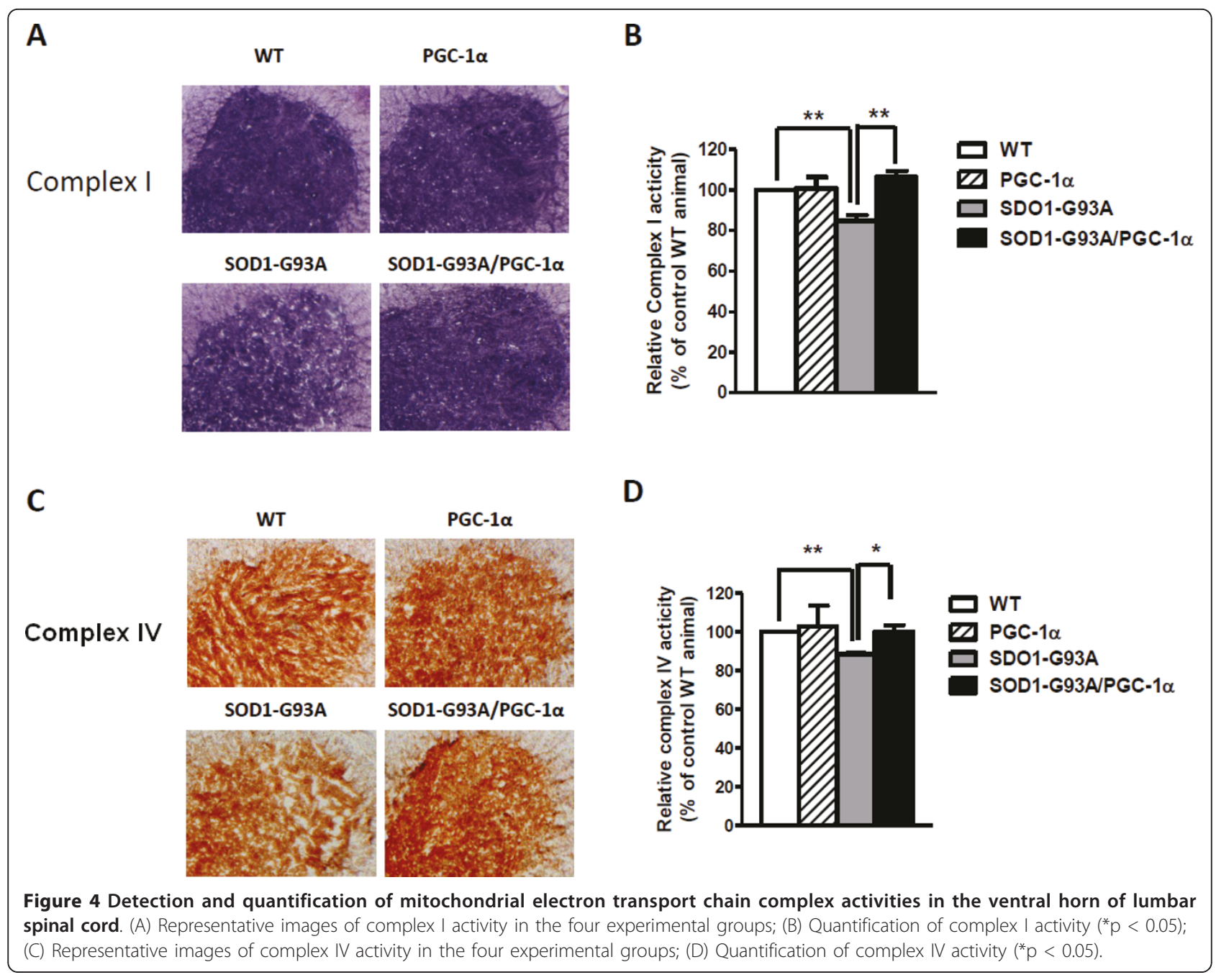

A

JNK

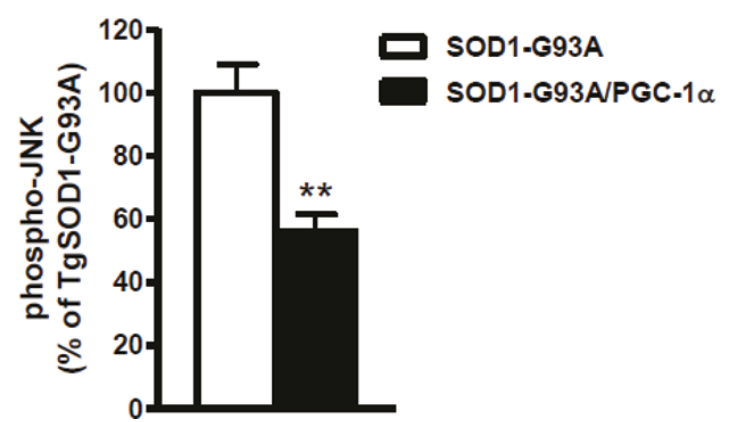

B

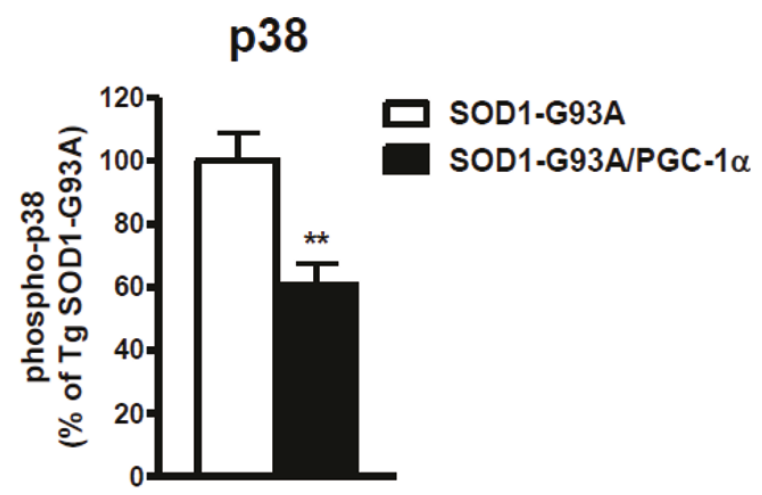

Figure 5 PGC-1 $\alpha$ inhibited phosphorylation of JNK and p38 MAPK. Bead-based multiplex luminex assay was performed to examine the phosphorylation of (A) JNK and (B) p38 MAPK. Mean fluorescence intensities were recorded and data were plotted as percentage of SOD1-G93A animals $\left({ }^{*} p<0.01\right)$. 
the last $4 \mathrm{~h}$ of the day portion of the light cycle in an environment with minimal stimuli such as noise, movement, or changes in light or temperature.

\section{Glucose Tolerance Test}

Mice were fasted overnight in clean cages with free access to water in new clean bottles. The next morning each mouse was weighed, and a baseline fasted blood glucose measurement was taken by applying tail blood to a Contour Blood Glucose Monitoring System (Bayer). Each mouse was injected intraperitonealy with a filtersterilized solution of $20 \%(\mathrm{w} / \mathrm{v}) \mathrm{D}$-glucose, with the size of the bolus determined by animal weight $(2 \mathrm{mg}$ glucose/g body weight). Blood glucose measurements were taken as described above for each animal at 15, 30, 60 and 120 minutes. The data were plotted as blood glucose concentration $(\mathrm{mg} / \mathrm{dL})$ over time (minutes).

\section{Luminex Assay}

A Bead-based multiplex luminex assay was performed using MILLIPLEX MAP 8-Plex Multi-Pathway Signaling Kit, Phosphoprotein (Millipore, Billerica, MA) following the manufacturer's protocols. Briefly, the spinal cords were homogenized in ice-cold Milliplex lysis buffer with protease inhibitors and then centrifuged at 12,000 rpm for 10 minutes at $4^{\circ} \mathrm{C}$. Protein concentration was measured using the Bradford method. $25 \mu \mathrm{g}$ protein of each sample was used for analysis.

\section{Preparation of Mouse Spinal Cord Sections}

Age and gender-matched wild type, TgSOD1-G93A, TgPGC- $1 \alpha$ and TgSOD1-G93A/TgPGC- $1 \alpha$ double transgenic mice were euthanized by ketamine and their spinal cords were dissected out. The lumbar region was separated and rapidly frozen under 2-methylbutane on dry ice. The samples were stored at $-80^{\circ} \mathrm{C}$ until sectioned. For sectioning, samples were embedded in OCT compound and transverse sections were cut at $-20^{\circ} \mathrm{C}$ using a Leica CM3050 cryostat. The sections were collected on positively-charged glass slides (Superfrost Plus, Fisher Scientific) and stored at $-80^{\circ} \mathrm{C}$ till use.

\section{Histology}

Ten serial sections ( $25 \mu \mathrm{m}$ thick) were cut $350 \mu \mathrm{m}$ apart through the lumbar (L3-L5) spinal cord of each animal $(\mathrm{n}=5)$. The sections were mounted onto Superfrost Plus slides and Nissl staining was performed using cresyl violet as previously described [33]. Large $(>25 \mu \mathrm{m})$, Nissl stained neurons were counted within the ventral horns under a light microscope at a magnification of 200.

\section{Histochemical Reaction, Imaging and Analysis}

$8 \mu \mathrm{m}$ thick sections of the lumbar spinal cord were air dried for $30 \mathrm{~min}$ and used for activity staining of mitochondrial complexes $[1,18]$. All the staining reactions were carried out at room temperature in the dark. To quantify complex I activity, the sections were incubated in $0.1 \mathrm{M}$ Tris- $\mathrm{HCl}$ ( $\mathrm{pH} 7.4$ ), $0.14 \mathrm{mM} \mathrm{NADH}, 1$ $\mathrm{mg} / \mathrm{ml}$ nitroblue tetrazolium, $2 \mu \mathrm{g} / \mathrm{ml}$ antimycin, 84 $\mathrm{mM}$ malonate and $2 \mathrm{mM}$ potassium cyanide. For complex II histochemistry, the enzyme was activated [34,35] by a $10 \mathrm{~min}$ incubation in $0.05 \mathrm{M}$ potassium phosphate buffer ( $\mathrm{pH}$ 7.4), followed by the addition of the reaction mix consisting of $4.5 \mathrm{mM}$ EDTA, $2 \mathrm{mg} / \mathrm{ml}$ nitroblue tetrazolium, $50 \mathrm{mM}$ succinate, $0.2 \mathrm{mM}$ phenazonium methosulfate, $2 \mu \mathrm{g} / \mathrm{ml}$ antimycin, $60 \mu \mathrm{M}$ rotenone and 2 $\mathrm{mM}$ potassium cyanide in the same buffer. The complex IV reaction required $75 \mathrm{mg} / \mathrm{ml}$ sucrose, $1 \mathrm{mg} / \mathrm{ml}$ diaminobenzidine $\mathrm{HCl}, 24 \mathrm{U} / \mathrm{ml}$ catalase, $1 \mathrm{mg} / \mathrm{ml}$ cytochrome c, $2 \mu \mathrm{g} / \mathrm{ml}$ antimycin, $60 \mu \mathrm{M}$ rotenone and 84 $\mathrm{mM}$ malonate in $0.05 \mathrm{M}$ potassium phosphate buffer ( $\mathrm{pH}$ 7.4). The negative controls contained $60 \mu \mathrm{M}$ rotenone, $84 \mathrm{mM}$ malonate or $2 \mathrm{mM}$ potassium cyanide to specifically inhibit complexes I, II or IV respectively. After incubations of $20 \mathrm{~min}$ for the complex I and IV reactions or $10 \mathrm{~min}$ for the complex II reaction, the sections were washed twice in phosphate buffered saline, once in distilled water and then mounted in glycerin jelly.

Stained sections were visualized under an Olympus MVX10 Macroview stereomicroscope controlled by MicroSuite Five Biological Suite software and photographed using the attached Hamamatsu C8484 monochrome camera. Images were taken with particular care to use uniform gray scales and below the level of saturation. Optical intensities of the ventral horn area on these sections were quantified using ImageJ software (NIH). Optical intensities were converted to optical densities (OD) by the formula: OD = $\log 10$ (Ibk/Im), where Ibk is background intensity and Im is measured intensities from different regions of the sections.

\section{Abbreviations}

ALS: amyotrophic lateral sclerosis; PPARGC1A or PGC-1a: peroxisome proliferator-activated receptor gamma co-activator-1a; SOD: copper-zinc superoxide dismutase; ETC: electron transport chain; NSE: neuron-specific enolase; JNK: c-jun N-terminal kinase; AD: Alzheimer's disease; PD: Parkinson's disease; HD: Huntington's disease;

\section{Author details}

${ }^{1}$ Department of Neurology, Mount Sinai School of Medicine, New York, NY 10029, USA. ${ }^{2}$ GRECC, James J. Peters Veterans Affairs Medical Center, Bronx, NY 10468, USA.

\section{Authors' contributions}

WZ: conceptualized the project, designed and carried out the experiments, analyzed data and drafted the manuscript; MV: carried out histochemical assays and participated in manuscript revision; SY: carried out vector construction; YP: carried out immunostaining; PV and FC: participated in animal motor function assessment; $\mathrm{AC}$ and $\mathrm{XQ}$ : contributed to animal care, genotyping and dissection; PM and $\mathrm{SH}$ : participated in histology and histochemical assays; GMP: involved in project conception and experimental 
design, data interpretation, manuscript preparation and final approval. All authors have read and approved this manuscript.

\section{Competing interests}

The authors declare that they have no competing interests.

Received: 23 November 2010 Accepted: 19 July 2011

Published: 19 July 2011

\section{References}

1. Pasinelli $\mathrm{P}$, Brown $\mathrm{RH}$ : Molecular biology of amyotrophic lateral sclerosis: insights from genetics. Nat Rev Neurosci 2006, 7:710-723.

2. Rosen DR, Siddique T, Patterson D, Figlewicz DA, Sapp P, Hentati A, Donaldson D, Goto J, O'Regan JP, Deng HX: Mutations in Cu/Zn superoxide dismutase gene are associated with familial amyotrophic lateral sclerosis. Nature 1993, 362:59-62.

3. Mattiazzi M, D'Aurelio M, Gajewski CD, Martushova K, Kiaei M, Beal MF Manfredi G: Mutated human SOD1 causes dysfunction of oxidative phosphorylation in mitochondria of transgenic mice. J Biol Chem 2002, 277:29626-29633.

4. Swerdlow RH, Parks JK, Cassarino DS, Trimmer PA, Miller SW, Maguire DJ, Sheehan JP, Maguire RS, Pattee G, Juel VC, Phillips LH, Tuttle JB, Bennett JP $\mathrm{Jr}$, Davis RE, Parker WD Jr: Mitochondria in sporadic amyotrophic lateral sclerosis. Exp Neurol 1998, 153:135-142.

5. Gurney ME, Pu H, Chiu AY, Dal Canto MC, Polchow CY, Alexander DD, Caliendo J, Hentati A, Kwon YW, Deng HX: Motor neuron degeneration in mice that express a human $\mathrm{Cu}, \mathrm{Zn}$ superoxide dismutase mutation. Science 1994, 264:1772-1775.

6. Bruijn LI, Miller TM, Cleveland DW: Unraveling the mechanisms involved in motor neuron degeneration in ALS. Annu Rev Neurosci 2004, 27:723-749.

7. Beal MF: Mitochondria and the pathogenesis of ALS. Brain 2000, 123(Pt 7):1291-1292.

8. Manfredi $G, X u Z$ : Mitochondrial dysfunction and its role in motor neuron degeneration in ALS. Mitochondrion 2005, 5:77-87.

9. Browne SE, Bowling AC, Baik MJ, Gurney M, Brown RH Jr, Beal MF: Metabolic dysfunction in familial, but not sporadic, amyotrophic lateral sclerosis. J Neurochem 1998, 71:281-287.

10. Bowling AC, Schulz JB, Brown RH Jr, Beal MF: Superoxide dismutase activity, oxidative damage, and mitochondrial energy metabolism in familial and sporadic amyotrophic lateral sclerosis. J Neurochem 1993, 61:2322-2325

11. Fukuchi K, Maruyama H, Takagi Y, Gomi K: Direct proteasome inhibition by clasto-lactacystin beta-lactone permits the detection of ubiquitinated p21(waf1) in ML-1 cells. Biochim Biophys Acta 1999, 1451:206-210.

12. Jung $C$, Higgins $C M, X u Z$ : Mitochondrial electron transport chain complex dysfunction in a transgenic mouse model for amyotrophic lateral sclerosis. J Neurochem 2002, 83:535-545.

13. Klivenyi P, Ferrante RJ, Matthews RT, Bogdanov MB, Klein AM, Andreassen OA, Mueller G, Wermer M, Kaddurah-Daouk R, Beal MF: Neuroprotective effects of creatine in a transgenic animal model of amyotrophic lateral sclerosis. Nat Med 1999, 5:347-350.

14. Lin J, Handschin C, Spiegelman BM: Metabolic control through the PGC-1 family of transcription coactivators. Cell Metab 2005, 1:361-370.

15. Arany Z, He H, Lin J, Hoyer K, Handschin C, Toka O, Ahmad F, Matsui T, Chin S, Wu PH, Rybkin II, Shelton JM, Manieri M, Cinti S, Schoen FJ, BasselDuby R, Rosenzweig A, Ingwall JS, Spiegelman BM: Transcriptional coactivator PGC-1 alpha controls the energy state and contractile function of cardiac muscle. Cell Metab 2005, 1:259-271.

16. Gurney ME, Pu H, Chiu AY, Dal Canto MC, Polchow CY, Alexander DD, Caliendo J, Hentati A, Kwon YW, Deng HX: Motor neuron degeneration in mice that express a human $\mathrm{Cu}, \mathrm{Zn}$ superoxide dismutase mutation. Science 1994, 264:1772-1775.

17. Pradat PF, Bruneteau G, Gordon PH, Dupuis L, Bonnefont-Rousselot D, Simon D, Salachas F, Corcia P, Frochot V, Lacorte JM, Jardel C, Coussieu C, Le FN, Lacomblez L, Loeffler JP, Meininger V: Impaired glucose tolerance in patients with amyotrophic lateral sclerosis. Amyotroph Lateral Scler 2010, 11:166-171.

18. Jung $C$, Higgins $C M, X u Z$ : A quantitative histochemical assay for activities of mitochondrial electron transport chain complexes in mouse spinal cord sections. J Neurosci Methods 2002, 114:165-172.
19. Perlson $E$, Jeong GB, Ross JL, Dixit R, Wallace KE, Kalb RG, Holzbaur EL: A switch in retrograde signaling from survival to stress in rapid-onset neurodegeneration. J Neurosci 2009, 29:9903-9917.

20. Tortarolo M, Veglianese P, Calvaresi N, Botturi A, Rossi C, Giorgini A, Migheli A, Bendotti C: Persistent activation of p38 mitogen-activated protein kinase in a mouse model of familial amyotrophic lateral sclerosis correlates with disease progression. Mol Cell Neurosci 2003, 23:180-192.

21. Williamson TL, Cleveland DW: Slowing of axonal transport is a very early event in the toxicity of ALS-linked SOD1 mutants to motor neurons. Nat Neurosci 1999, 2:50-56.

22. Ackerley S, Grierson AJ, Banner S, Perkinton MS, Brownlees J, Byers HL, Ward M Thornhill P, Hussain K, Waby JS, Anderton BH, Cooper JD, Dingwall C, Leigh PN Shaw CE, Miller CC: p38alpha stress-activated protein kinase phosphorylates neurofilaments and is associated with neurofilament pathology in amyotrophic lateral sclerosis. Mol Cell Neurosci 2004, 26:354-364.

23. De VK, Severin F, Van HF, Vancompernolle K, Goossens V, Hyman A, Grooten J: Tumor necrosis factor induces hyperphosphorylation of kinesin light chain and inhibits kinesin-mediated transport of mitochondria. J Cell Biol 2000, 149:1207-1214.

24. Morfini G, Pigino G, Szebenyi G, You Y, Pollema S, Brady ST: JNK mediates pathogenic effects of polyglutamine-expanded androgen receptor on fast axonal transport. Nat Neurosci 2006, 9:907-916.

25. Zheng B, Liao Z, Locascio JJ, Lesniak KA, Roderick SS, Watt ML, Eklund AC, Zhang-James Y, Kim PD, Hauser MA, Grunblatt E, Moran LB, Mandel SA, Riederer P, Miller RM, Federoff HJ, Wullner U, Papapetropoulos S, Youdim MB, Cantuti-Castelvetri I, Young AB, Vance JM, Davis RL, Hedreen JC, Adler CH, Beach TG, Graeber MB, Middleton FA, Rochet JC, Scherzer CR: PGC-1alpha, a potential therapeutic target for early intervention in Parkinson's disease. Sci Transl Med 2010, 2:52ra73.

26. Qin W, Haroutunian V, Katsel P, Cardozo CP, Ho L, Buxbaum JD, Pasinetti GM: PGC-1alpha expression decreases in the Alzheimer disease brain as a function of dementia. Arch Neurol 2009, 66:352-361.

27. Cui L, Jeong $H$, Borovecki F, Parkhurst CN, Tanese N, Krainc D: Transcriptional repression of PGC-1alpha by mutant huntingtin leads to mitochondrial dysfunction and neurodegeneration. Cell 2006, 127:59-69.

28. Chaturvedi RK, Adhihetty P, Shukla S, Hennessy T, Calingasan N, Yang L, Starkov A, Kiaei M, Cannella M, Sassone J, Ciammola A, Squitieri F, Beal MF: Impaired PGC-1alpha function in muscle in Huntington's disease. Hum Mol Genet 2009, 18:3048-3065.

29. Kiaei M, Kipiani K, Chen J, Calingasan NY, Beal MF: Peroxisome proliferatoractivated receptor-gamma agonist extends survival in transgenic mouse model of amyotrophic lateral sclerosis. Exp Neurol 2005, 191:331-336.

30. Schutz B, Reimann J, Dumitrescu-Ozimek L, Kappes-Horn K, Landreth GE, Schurmann B, Zimmer A, Heneka MT: The oral antidiabetic pioglitazone protects from neurodegeneration and amyotrophic lateral sclerosis-like symptoms in superoxide dismutase-G93A transgenic mice. J Neurosci 2005, 25:7805-7812.

31. Qin W, Yang T, Ho L, Zhao Z, Wang J, Chen L, Zhao W, Thiyagarajan M, MacGrogan D, Rodgers JT, Puigserver P, Sadoshima J, Deng H, Pedrini S Gandy S, Sauve AA, Pasinetti GM: Neuronal SIRT1 activation as a novel mechanism underlying the prevention of Alzheimer disease amyloid neuropathology by calorie restriction. J Biol Chem 2006, 281:21745-21754.

32. Kelley KA, Ho L, Winger D, Freire-Moar J, Borelli CB, Aisen PS, Pasinetti GM: Potentiation of excitotoxicity in transgenic mice overexpressing neuronal cyclooxygenase-2. Am J Pathol 1999, 155:995-1004.

33. varez-Buylla A, Ling CY, Kirn JR: Cresyl violet: a red fluorescent Nissl stain. J Neurosci Methods 1990, 33:129-133.

34. Brouillet E, Guyot MC, Mittoux V, Altairac S, Conde F, Palfi S, Hantraye P: Partial inhibition of brain succinate dehydrogenase by 3-nitropropionic acid is sufficient to initiate striatal degeneration in rat. J Neurochem 1998, 70:794-805.

35. Pandey $M$, Varghese $M$, Sindhu KM, Sreetama S, Navneet AK, Mohanakumar KP, Usha R: Mitochondrial NAD+-linked State 3 respiration and complex-I activity are compromised in the cerebral cortex of 3nitropropionic acid-induced rat model of Huntington's disease. $J$ Neurochem 2008, 104:420-434.

doi:10.1186/1750-1326-6-51

Cite this article as: Zhao et al:: Peroxisome proliferator activator receptor gamma coactivator-1alpha (PGC-1 1 ) improves motor performance and survival in a mouse model of amyotrophic lateral sclerosis. Molecular Neurodegeneration 2011 6:51. 